\title{
Controls of Nuclear Factor-Kappa B Signaling Activity by 5'-AMP-Activated Protein Kinase Activation With Examples in Human Bladder Cancer Cells
}

\author{
Bo-Hwa Choi ${ }^{1}$, Da-Hyun Lee ${ }^{1}$, Jin Kim² ${ }^{2}$ Ju-Hee Kang ${ }^{1}$, Chang-Shin Park ${ }^{1}$ \\ ${ }^{1}$ Department of Pharmacology, Hypoxia-Related Disease Research Center, Inha Research Institute for Medical Sciences, Inha University College of Medicine, \\ Incheon, Korea \\ ${ }^{2}$ Department of Anesthesiology and Pain Medicine, Inha University College of Medicine, Incheon, Korea
}

Generally, both lipopolysaccharide (LPS)- and hypoxia-induced nuclear factor kappa B (NF- $\mathrm{B}$ ) effects are alleviated through differential posttranslational modification of NF- $\mathrm{kB}$ phosphorylation after pretreatment with $5^{\prime}$-AMP-activated protein kinase (AMPK) activators such as 5'-aminoimidazole-4-carboxamide ribonucleotide (AICAR) or the hypoglycemic agent metformin. We found that AICAR or metformin acts as a regulator of LPS/NF- $\mathrm{kB}-$ or hypoxia/NF- $\mathrm{kB}$-mediated cyclooxygenase induction by an AMPK-dependent mechanism with interactions between p65-NF- $\mathrm{BB}$ phosphorylation and acetylation, including in a human bladder cancer cell line (T24). In summary, we highlighted the regulatory interactions of AMPK activity on NF- $\mathrm{KB}$ induction, particularly in posttranslational phosphorylation and acetylation of NF- $\mathrm{KB}$ under inflammatory conditions or hypoxia environment.

Keywords: NF-kappa B; AMP-Activated Protein Kinases; Lipopolysaccharides; Hypoxia

- Fund Support: This work was financially supported by a Medical Research Center (2014009392) through the National Research Foundation of Korea (NRF) funded by the Ministry of Science, ICT, and Future Planning.

- Conflict of Interest: No potential conflict of interest relevant to this article was reported.

\section{NUCLEAR FACTOR-KAPPA B ACTIVATION: PHOSPHORYLATION AND ACETYLATION}

The transcriptional factor nuclear factor kappa $\mathrm{B}(\mathrm{NF}-\kappa \mathrm{B})$ is a main regulator of the induction of several genes including inflammatory and immune response genes and the proliferation and death of cancer cells [1-4]. Cellular stimulation by pro-inflammatory cytokines, gram-negative bacterial lipopolysaccharide (LPS), viral infection, radiation, and hypoxia is induced by

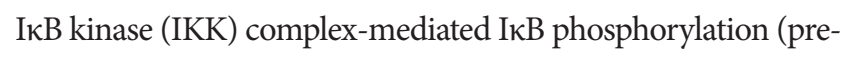

dominant form, IKK $\beta$ ) and ubiquitination, and degradation [510]. The mammalian NF- $\kappa B$ family consists of 5 subunits, p50NF- $\kappa$ B1, p52-NF- $\mathrm{B} 2$, c-Rel, p65-RelA, and RelB, which forms homo- or heterodimers of functional complexes.

$\mathrm{NF}-\kappa \mathrm{B}$ activity is regulated by its subcellular localization in the cytoplasm or nucleus. The NF- $\mathrm{kB}$ dimer is mainly sequestered in the cytoplasm as a complex associated with the $I \kappa B$ inhibitor in unstimulated resting cells, or rarely in the nucleus as a transcriptionally inactive complex shuttle [11]. In activated cells, I $\kappa \mathrm{B}$-free NF- $\kappa \mathrm{B}$ translocates into the nucleus where it acti-

Corresponding author: Chang-Shin Park (D) http://orcid.org/0000-0001-6519-2857 Department of Pharmacology \& Medicinal Toxicology Research Center, HypoxiaRelated Disease Research Center, Inha Research Institute for Medical Sciences, Inha University College of Medicine, 100 Inha-ro, Nam-gu, Incheon 22212, Korea E-mail: parkshin@inha.ac.kr / Tel: +82-32-860-9871 / Fax: +82-32-887-7488 Submitted: September 20, 2016 / Accepted after revision: September 26, 2016

(1) $\$$ This is an Open Access article distributed under the terms of the Creative Commons Attribution Non-Commercial License (http://creativecommons.org/licenses/by-nc/4.0/) which permits unrestricted non-commercial use, distribution, and reproduction in any medium, provided the original work is properly cited. 
vates the transcription of several genes, including newly synthesized I $\kappa B$. In addition to translocation of NF- $\mathrm{BB}$, the transcriptional activities of NF- $\kappa \mathrm{B}$ are regulated by posttranslational modifications such as phosphorylation and acetylation of p65NF- $\mathrm{KB}$ subunit for full activation [12-14]. The transcriptional activities of p65-NF- $\mathrm{kB}$, which are specifically targeted by several kinases, are highly enhanced by phosphorylation of $\mathrm{Ser}^{536}$, or Ser ${ }^{276}$, and $\mathrm{Ser}^{311}$ (by zetaPKC) in association with the coactivator $\mathrm{CBP} / \mathrm{p} 300[15,16]$. Additionally, Anrather et al. [17] reported 3 phosphorylation sites at $\operatorname{Ser}^{205}$ (induced by LPS), $\operatorname{Ser}^{276}$ (by MSK1), and Ser ${ }^{281}$ (by LPS and unknown kinase) as essential phosphorylation sites for transcriptional activity.

Phosphorylation of p65-NF- $\mathrm{kB}$ at Ser ${ }^{536}$ leads to nuclear translocation or cytoplasmic priming, and the transactivation mechanism is the target of several kinases including the important kinase IKK $\beta$ [18-20]. Phosphorylation of Ser ${ }^{281}$ has been studied with other related phosphorylation sites, including $\mathrm{Ser}^{205}$ and Ser ${ }^{276}$, to evaluate transactivation [17,21-23]. Anrather et al. [17] identified $\mathrm{Ser}^{205}, \mathrm{Ser}^{276}$, and $\mathrm{Ser}^{281}$ as potential phospho-acceptor sites within the p65 Rel homology domain, and found that both $\mathrm{Ser}^{205}$ and $\mathrm{Ser}^{276}$ can be mediated by Ser/Thr kinases, but Ser ${ }^{281}$ Ser-specific kinases alter transcriptional NF- $\mathrm{kB}$ activities when Ser is substituted with Thr. They suggested that the phosphorylation levels of these potential sites can affect the interaction of NF- $\mathrm{kB}$ with coactivators, and to acetylation patterns for the full NF- $\kappa B$ transcriptional activities. Additionally, p65-NF- $\kappa B$ phosphorylation levels reflect the differential NF$\kappa \mathrm{B}$ transcriptional activity of related gene subsets; however, phosphorylation is not essential for NF- $\kappa B$ DNA binding [23]. It was previously shown that the transcriptional coactivators p300 and CBP mainly acetylate p65-NF- $\mathrm{KB} \mathrm{Lys}{ }^{218}$ Lys $^{221}$, and Lys $^{310 n}[24,25]$. Particularly, p65-NF- $k B$ Lys ${ }^{310}$ acetylation stimulates the full transcriptional activity of p65-NF- $\mathrm{kB}$, but is only minimally related to DNA binding or I $\mathrm{B}$ assembly.

\section{AMPK ACTIVATION}

5'-AMP-activated protein kinase (AMPK) is a highly conserved serine/threonine protein kinase that regulates energy homeostasis and metabolic stress, and exists in all eukaryotic cells as heterotrimeric complexes comprising catalytic $\alpha$-subunits and regulatory $\beta$ - and $\gamma$-subunits. Phosphorylation of the $\mathrm{Thr}^{172}$ residue of the a subunit is important for maximum AMPK activity [26-28]. Three upstream kinases have been shown to activate AMPK. LKB1 stimulates AMPK in response to changes in the cellular AMP/ATP ratio, calmodulin-dependent protein kinase kinase $\beta$ in response to intracellular $\mathrm{Ca}^{2+}$ concentration, and transforming growth factor-beta-activating kinase 1 by immunological cytokines [29-32].

\section{INTERACTIONS BETWEEN NF- $K B$ INDUCTION AND AMPK ACTIVATION}

In recent years, numerous studies have reported the effects of AMPK activities on inflammatory NF-kB activity [33-48]. The major function of AMPK in inhibiting inflammation has been demonstrated using a known AMPK activator and the pharmacological mimetic 5' -aminoimidazole-4-carboxamide ribonucleotide (AICAR). Other studies showed that AICAR inhibits tumor necrosis factor (TNF)- $\alpha$ and interleukin- $\beta$-induced NF$\kappa \mathrm{B}$ activities in immune cells [49-52] and inducible nitric oxide synthase and cyclooxygenase (COX-2) expression levels in LPSor cytokine-stimulated myocytes, adipocytes, or macrophages grown in culture $[53,54]$. However, the anti-inflammatory effects of AICAR were also found to be AMPK-independent or nonspecific activators of AMPK in several studies $[52,55]$.

In addition to AICAR, there are several AMPK activators; metformin, used to treat type 2 diabetes; berberine, a natural product used in traditional Chinese medicine; and A-769662, derived from a high-throughput screen for AMPK activators [56,57]. Aspirin and salicylate also inhibit the inflammatory $\mathrm{NF}-\mathrm{\kappa B}$ pathway, and it has been proposed that this results from inhibition of the upstream kinase IKK- $\beta$ [58]. However, they suggested that inhibition of the NF- $\kappa B$ pathway is mediated by AMPK activation, rather than by direct inhibition of IKK- $\beta$. Overall, all AMPK activators described above have been reported to inhibit inflammatory responses in various model systems.

\section{Example 1 (Unpublished): Effects of AMPK Activator on LPS- or Hypoxia-Induced NF-kB Phosphorylation and Acetylation Activities in the Human Bladder Cancer Cell Line T24}

We recently investigated the effects of LPS and the AMPK activator AICAR on COX-2 induction, two specific p65-NF- $\kappa B$ phospho-activities $\left(\mathrm{Ser}^{56}\right.$ and $\mathrm{Ser}^{281}$ ), and the acetylation activity of p65-NF- $k B$ Lys ${ }^{310}$. Particularly, we proposed that the expression levels of p65-NF- $\mathrm{B}$ Ser ${ }^{281}$ phosphorylation and p65-NF$\kappa B$ Lys $^{310}$ acetylation were inversed, suggesting potential inhibitory activity of p65-NF- $\kappa B$ Ser ${ }^{281}$ phosphorylation. Both LPSand hypoxia-induced NF- $\kappa$ B activities in a human bladder can- 
cer line T24 were alleviated by pretreatment with AICAR. Additionally, AMPK siRNA-mediated suppression enhanced NFкB-mediated COX-2 induction by LPS or hypoxia. Particularly, we suggested that direct interactions and colocalization occur between $\mathrm{p}$-AMPK (at phospho-activation site $\mathrm{Thr}^{172}$ ) (pAMPK) and IкBa-free NF- $\kappa B$, especially in nucleus. LPS-induced full transcriptional activity of NF- $\kappa \mathrm{B}$, as indicated by a critical acetylation level (Ac-K310 p65-NF-kB), was decreased by AICAR pretreatment, whereas the phosphorylation level at p65-NF-kB Ser ${ }^{281}$ was increased [35].

\section{Example 2 (Unpublished): Transient Inactivation of AMPK and ROS Participation After LPS Treatment in the Human Bladder Cancer Line T24}

We also found that AMPK phosphorylation as well as the ability of AICAR to enhance phosphorylation of AMPK was decreased only at the early time ( $\sim 1$ hour) after LPS stimulation. This effect of LPS stimulation on p-AMPK levels was abolished or showed a greater increase at the later time (after 16 hours). Recently, Sag et al. [59] and Tadie et al. [60] demonstrated that the transient suppression of AMPK phosphorylation diminished the ability of AICAR to increase AMPK phosphorylation in LPS-stimulated cells. In particular, Tadie et al. [60] suggested that HMGB1 released form injured or necrotic cells was involved in decreasing LPS-treated AMPK phospho-activity based on their results showing an inverse relationship between accumulated HMGB1 in cytoplasm and AMPK phosphorylation levels. Furthermore, we examined $N$-acetyl cystein (NAC) pretreatment under the above experimental conditions to immediately inhibit reactive oxygen species (ROS) release at the early time, which resulted in increased p-AMPK levels and decreased COX-2 induction. Thus, our finding may also be explained by the influence of early released ROS on AMPK phospho-activity in LPS-stimulated bladder cancer cells.

Based on our findings, AICAR pretreatment partially decreased both LPS- and hypoxia-treated COX-2 induction. Additionally, LPS-induced NF-kB p65 Ser ${ }^{536}$ phospho-activity was decreased by AICAR pretreatment, but highly increased by AMPK-siRNA, suggesting an AMPK-dependent mechanism. Consistent with this result, recent studies reported the ability of AICAR to suppress NF- $\kappa B$ activation in response to LPS or pro-inflammatory cytokines through an AMPK-dependent or -independent mechanism [52,59-61].

\section{Example 3 (Unpublished): Differential Activities of AMPK and Activation of NF-KB Signaling Pathways Under Inflammatory or Hypoxia Conditions}

It is generally known that the TLR4/NF- $\mathrm{BB}$ signaling pathway is activated under hypoxic conditions, increasing the gene expression of downstream inflammatory mediators [7,8,57,6267]. Additionally, hypoxia induces AMPK activation in cancer cells as a survival mechanism by ATP-depletion (Laderoute et al. [66], 2006; Miller et al. [67], 2008; Kim et al. [57], 2012). In contrast, the phospho-activities of the serial enzymes p-LKB1, p-AMPK, and p-ACC in our study were time-dependently diminished under hypoxia conditions and HIFla expression was increased (unpublished). In addition, p-AMPK levels after LPS, AICAR, or NAC treatment and even in untreated cells were decreased under hypoxia conditions, and hypoxia-induced COX2 expression was synergistically enhanced by additional treatment with LPS and blocked or decreased by AICAR pretreatment; these results are similar to those of other recent reports $[9,10]$.

\section{CONCLUSIONS}

In this short review, we highlighted the regulatory interactions of AMPK activity on NF- $\mathrm{KB}$ induction, particularly in posttranslational phosphorylation and acetylation of NF- $\mathrm{kB}$ under inflammatory conditions or in hypoxia environments, providing examples in the human bladder cancer cell line T24.

\section{REFERENCES}

1. Pahl HL. Activators and target genes of Rel/NF-kappaB transcription factors. Oncogene 1999;18:6853-66.

2. Karin M, Cao Y, Greten FR, Li ZW. NF-kappaB in cancer: from innocent bystander to major culprit. Nat Rev Cancer 2002;2:301-10.

3. Karin M, Lin A. NF-kappaB at the crossroads of life and death. Nat Immunol 2002;3:221-7.

4. Hayden MS, West AP, Ghosh S. NF-kappaB and the immune response. Oncogene 2006;25:6758-80.

5. Henkel T, Machleidt T, Alkalay I, Krönke M, Ben-Neriah Y, Baeuerle PA. Rapid proteolysis of I kappa B-alpha is necessary for activation of transcription factor NF-kappa B. Nature 1993;365:182-5.

6. Spencer E, Jiang J, Chen ZJ. Signal-induced ubiquitination of IkappaBalpha by the F-box protein Slimb/beta-TrCP. Genes Dev 1999;13:284-94.

7. Jung YJ, Isaacs JS, Lee S, Trepel J, Neckers L. IL-1beta-mediated up- 
regulation of HIF-1alpha via an NFkappaB/COX-2 pathway identifies HIF-1 as a critical link between inflammation and oncogenesis. FASEB J 2003;17:2115-7.

8. Hara Y, Shiraishi A, Ohashi Y. Hypoxia-altered signaling pathways of toll-like receptor 4 (TLR4) in human corneal epithelial cells. Mol Vis 2009;15:2515-20.

9. Bruning U, Fitzpatrick SF, Frank T, Birtwistle M, Taylor CT, Cheong A. NFkB and HIF display synergistic behaviour during hypoxic inflammation. Cell Mol Life Sci 2012;69:1319-29.

10. Lei Q, Qiang F, Chao D, Di W, Guoqian Z, Bo Y, et al. Amelioration of hypoxia and LPS-induced intestinal epithelial barrier dysfunction by emodin through the suppression of the NF-kB and HIF- $1 \alpha$ signaling pathways. Int J Mol Med 2014;34:1629-39.

11. Arenzana-Seisdedos F, Thompson J, Rodriguez MS, Bachelerie F, Thomas D, Hay RT. Inducible nuclear expression of newly synthesized I kappa B alpha negatively regulates DNA-binding and transcriptional activities of NF-kappa B. Mol Cell Biol 1995;15:2689-96.

12. Zhong H, SuYang H, Erdjument-Bromage H, Tempst P, Ghosh S. The transcriptional activity of NF-kappaB is regulated by the IkappaB-associated PKAc subunit through a cyclic AMP-independent mechanism. Cell 1997;89:413-24.

13. Wang D, Baldwin AS Jr. Activation of nuclear factor-kappaB-dependent transcription by tumor necrosis factor-alpha is mediated through phosphorylation of RelA/p65 on serine 529. J Biol Chem 1998;273:29411-6.

14. Chen LF, Mu Y, Greene WC. Acetylation of RelA at discrete sites regulates distinct nuclear functions of NF-kappaB. EMBO J 2002; 21:6539-48.

15. Zhong H, Voll RE, Ghosh S. Phosphorylation of NF-kappa B p65 by PKA stimulates transcriptional activity by promoting a novel bivalent interaction with the coactivator CBP/p300. Mol Cell 1998; 1:661-71.

16. Duran A, Diaz-Meco MT, Moscat J. Essential role of RelA Ser311 phosphorylation by zetaPKC in NF-kappaB transcriptional activation. ЕMBO J 2003;22:3910-8.

17. Anrather J, Racchumi G, Iadecola C. cis-acting, element-specific transcriptional activity of differentially phosphorylated nuclear factor-kappa B. J Biol Chem 2005;280:244-52.

18. Sakurai H, Chiba H, Miyoshi H, Sugita T, Toriumi W. IkappaB kinases phosphorylate NF-kappaB p65 subunit on serine 536 in the transactivation domain. J Biol Chem 1999;274:30353-6.

19. Haller D, Russo MP, Sartor RB, Jobin C. IKK beta and phosphatidylinositol 3-kinase/Akt participate in non-pathogenic Gram-negative enteric bacteria-induced RelA phosphorylation and NF-kappa B activation in both primary and intestinal epithelial cell lines. J
Biol Chem 2002;277:38168-78.

20. Mattioli I, Sebald A, Bucher C, Charles RP, Nakano H, Doi T, et al. Transient and selective NF-kappa B p65 serine 536 phosphorylation induced by $\mathrm{T}$ cell costimulation is mediated by I kappa B kinase beta and controls the kinetics of p65 nuclear import. J Immunol 2004;172:6336-44.

21. Hochrainer K, Racchumi G, Anrather J. Hypo-phosphorylation leads to nuclear retention of NF-kappaB p65 due to impaired IkappaBalpha gene synthesis. FEBS Lett 2007;581:5493-9.

22. Pejanovic N, Hochrainer K, Liu T, Aerne BL, Soares MP, Anrather J. Regulation of nuclear factor $\mathrm{\kappa B}(\mathrm{NF}-\mathrm{kB})$ transcriptional activity via p65 acetylation by the chaperonin containing TCP1 (CCT). PLoS One 2012;7:e42020.

23. Hochrainer K, Racchumi G, Anrather J. Site-specific phosphorylation of the p65 protein subunit mediates selective gene expression by differential NF- $\mathrm{kB}$ and RNA polymerase II promoter recruitment. J Biol Chem 2013;288:285-93.

24. Chen JJ. Regulation of protein synthesis by the heme-regulated eIF2alpha kinase: relevance to anemias. Blood 2007;109:2693-9.

25. Chen LF, Greene WC. Shaping the nuclear action of NF-kappaB. Nat Rev Mol Cell Biol 2004;5:392-401.

26. Hawley SA, Davison M, Woods A, Davies SP, Beri RK, Carling D, et al. Characterization of the AMP-activated protein kinase kinase from rat liver and identification of threonine 172 as the major site at which it phosphorylates AMP-activated protein kinase. J Biol Chem 1996;271:27879-87.

27. Hardie DG, Carling D. The AMP-activated protein kinase--fuel gauge of the mammalian cell? Eur J Biochem 1997;246:259-73.

28. Hardie DG, Scott JW, Pan DA, Hudson ER. Management of cellular energy by the AMP-activated protein kinase system. FEBS Lett 2003;546:113-20.

29. Woods A, Dickerson K, Heath R, Hong SP, Momcilovic M, Johnstone SR, et al. Ca2+/calmodulin-dependent protein kinase kinasebeta acts upstream of AMP-activated protein kinase in mammalian cells. Cell Metab 2005;2:21-33.

30. Xie M, Zhang D, Dyck JR, Li Y, Zhang H, Morishima M, et al. A pivotal role for endogenous TGF-beta-activated kinase-1 in the LKB1/AMP-activated protein kinase energy-sensor pathway. Proc Natl Acad Sci U S A 2006;103:17378-83.

31. Sanders MJ, Grondin PO, Hegarty BD, Snowden MA, Carling D. Investigating the mechanism for AMP activation of the AMP-activated protein kinase cascade. Biochem J 2007;403:139-48.

32. Herrero-Martín G, Høyer-Hansen M, García-García C, Fumarola C, Farkas T, López-Rivas A, et al. TAK1 activates AMPK-dependent cytoprotective autophagy in TRAIL-treated epithelial cells. 
EMBO J 2009;28:677-85.

33. Zhao X, Zmijewski JW, Lorne E, Liu G, Park YJ, Tsuruta Y, et al. Activation of AMPK attenuates neutrophil proinflammatory activity and decreases the severity of acute lung injury. Am J Physiol Lung Cell Mol Physiol 2008;295:L497-504.

34. Andreasen AS, Kelly M, Berg RM, Møller K, Pedersen BK. Type 2 diabetes is associated with altered NF- $\mathrm{kB}$ DNA binding activity, JNK phosphorylation, and AMPK phosphorylation in skeletal muscle after LPS. PLoS One 2011;6:e23999.

35. Barroso E, Eyre E, Palomer X, Vázquez-Carrera M. The peroxisome proliferator-activated receptor $\beta / \delta(\operatorname{PPAR} \beta / \delta)$ agonist GW501516 prevents TNF- $\alpha$-induced NF- $\kappa B$ activation in human HaCaT cells by reducing p65 acetylation through AMPK and SIRT1. Biochem Pharmacol 2011;81:534-43.

36. Green CJ, Macrae K, Fogarty S, Hardie DG, Sakamoto K, Hundal HS. Counter-modulation of fatty acid-induced pro-inflammatory nuclear factor $\kappa B$ signalling in rat skeletal muscle cells by AMP-activated protein kinase. Biochem J 2011;435:463-74.

37. Green CJ, Pedersen M, Pedersen BK, Scheele C. Elevated NF- $\kappa B$ activation is conserved in human myocytes cultured from obese type 2 diabetic patients and attenuated by AMP-activated protein kinase. Diabetes 2011;60:2810-9.

38. Kubota S, Ozawa Y, Kurihara T, Sasaki M, Yuki K, Miyake S, et al. Roles of AMP-activated protein kinase in diabetes-induced retinal inflammation. Invest Ophthalmol Vis Sci 2011;52:9142-8.

39. Zhang Y, Qiu J, Wang X, Zhang Y, Xia M. AMP-activated protein kinase suppresses endothelial cell inflammation through phosphorylation of transcriptional coactivator p300. Arterioscler Thromb Vasc Biol 2011;31:2897-908.

40. Ji G, Zhang Y, Yang Q, Cheng S, Hao J, Zhao X, et al. Genistein suppresses LPS-induced inflammatory response through inhibiting NF- $\kappa$ B following AMP kinase activation in RAW 264.7 macrophages. PLoS One 2012;7:e53101.

41. Kim HS, Kim MJ, Kim EJ, Yang Y, Lee MS, Lim JS. Berberine-induced AMPK activation inhibits the metastatic potential of melanoma cells via reduction of ERK activity and COX-2 protein expression. Biochem Pharmacol 2012;83:385-94.

42. Moiseeva O, Deschênes-Simard X, St-Germain E, Igelmann S, Huot G, Cadar AE, et al. Metformin inhibits the senescence-associated secretory phenotype by interfering with IKK/NF- $\kappa B$ activation. Aging Cell 2013;12:489-98.

43. Jiménez-Flores LM, López-Briones $\mathrm{S}$, Macías-Cervantes $\mathrm{MH}$, Ramírez-Emiliano J, Pérez-Vázquez V. A PPAR $\gamma, \mathrm{NF}-\kappa \mathrm{B}$ and AMPK-dependent mechanism may be involved in the beneficial effects of curcumin in the diabetic $\mathrm{db} / \mathrm{db}$ mice liver. Molecules
2014;19:8289-302.

44. Li J, Li J, Yue Y, Hu Y, Cheng W, Liu R, et al. Genistein suppresses tumor necrosis factor $\alpha$-induced inflammation via modulating reactive oxygen species/Akt/nuclear factor $\mathrm{\kappa B}$ and adenosine monophosphate-activated protein kinase signal pathways in human synoviocyte MH7A cells. Drug Des Devel Ther 2014;8:315-23.

45. Mo C, Wang L, Zhang J, Numazawa S, Tang H, Tang X, et al. The crosstalk between Nrf2 and AMPK signal pathways is important for the anti-inflammatory effect of berberine in LPS-stimulated macrophages and endotoxin-shocked mice. Antioxid Redox Signal 2014;20:574-88.

46. Nalli AD, Kumar DP, Mahavadi S, Al-Shboul O, Alkahtani R, Kuemmerle JF, et al. Hypercontractility of intestinal longitudinal smooth muscle induced by cytokines is mediated by the nuclear factor- $\mathrm{B} / \mathrm{AMP}$-activated kinase/myosin light chain kinase pathway. J Pharmacol Exp Ther 2014;350:89-98.

47. Tsai KL, Huang PH, Kao CL, Leu HB, Cheng YH, Liao YW, et al. Aspirin attenuates vinorelbine-induced endothelial inflammation via modulating SIRT1/AMPK axis. Biochem Pharmacol 2014;88: 189-200.

48. Huang BP, Lin CH, Chen HM, Lin JT, Cheng YF, Kao SH. AMPK activation inhibits expression of proinflammatory mediators through downregulation of PI3K/p38 MAPK and NF- $\mathrm{kB}$ signaling in murine macrophages. DNA Cell Biol 2015;34:133-41.

49. Giri S, Nath N, Smith B, Viollet B, Singh AK, Singh I. 5-aminoimidazole-4-carboxamide-1-beta-4-ribofuranoside inhibits proinflammatory response in glial cells: a possible role of AMP-activated protein kinase. J Neurosci 2004;24:479-87.

50. Jin Q, Jhun BS, Lee SH, Lee J, Pi Y, Cho YH, et al. Differential regulation of phosphatidylinositol 3-kinase/Akt, mitogen-activated protein kinase, and AMP-activated protein kinase pathways during menadione-induced oxidative stress in the kidney of young and old rats. Biochem Biophys Res Commun 2004;315:555-61.

51. Levine YC, Li GK, Michel T. Agonist-modulated regulation of AMP-activated protein kinase (AMPK) in endothelial cells. Evidence for an AMPK->Rac1->Akt->endothelial nitric-oxide synthase pathway. J Biol Chem 2007;282:20351-64.

52. Kuo CL, Ho FM, Chang MY, Prakash E, Lin WW. Inhibition of lipopolysaccharide-induced inducible nitric oxide synthase and cyclooxygenase- 2 gene expression by 5-aminoimidazole-4-carboxamide riboside is independent of AMP-activated protein kinase. J Cell Biochem 2008;103:931-40.

53. Centeno-Baez C, Dallaire P, Marette A. Resveratrol inhibition of inducible nitric oxide synthase in skeletal muscle involves AMPK but not SIRT1. Am J Physiol Endocrinol Metab 2011;301:E922-30. 
54. Wang L, Li L, Ran X, Long M, Zhang M, Tao Y, et al. Lipopolysaccharides reduce adipogenesis in 3T3-L1 adipocytes through activation of NF- $\kappa$ B pathway and downregulation of AMPK expression. Cardiovasc Toxicol 2013;13:338-46.

55. Jhun BS, Jin Q, Oh YT, Kim SS, Kong Y, Cho YH, et al. 5-Aminoimidazole-4-carboxamide riboside suppresses lipopolysaccharideinduced TNF-alpha production through inhibition of phosphatidylinositol 3-kinase/Akt activation in RAW 264.7 murine macrophages. Biochem Biophys Res Commun 2004;318:372-80.

56. Göransson O, McBride A, Hawley SA, Ross FA, Shpiro N, Foretz M, et al. Mechanism of action of A-769662, a valuable tool for activation of AMP-activated protein kinase. J Biol Chem 2007;282:32549-60.

57. Kim HS, Wannatung T, Lee S, Yang WK, Chung SH, Lim JS, et al. Quercetin enhances hypoxia-mediated apoptosis via direct inhibition of AMPK activity in HCT116 colon cancer. Apoptosis 2012;17: 938-49.

58. Hawley SA, Fullerton MD, Ross FA, Schertzer JD, Chevtzoff C, Walker KJ, et al. The ancient drug salicylate directly activates AMPactivated protein kinase. Science 2012;336:918-22.

59. Sag D, Carling D, Stout RD, Suttles J. Adenosine 5'-monophosphate-activated protein kinase promotes macrophage polarization to an anti-inflammatory functional phenotype. J Immunol 2008; 181:8633-41.

60. Tadie JM, Bae HB, Deshane JS, Bell CP, Lazarowski ER, Chaplin DD, et al. Toll-like receptor 4 engagement inhibits adenosine 5'-monophosphate-activated protein kinase activation through a high mobility group box 1 protein-dependent mechanism. Mol Med 2012;18:
659-68.

61. Prasad R, Giri S, Nath N, Singh I, Singh AK. 5-aminoimidazole4-carboxamide-1-beta-4-ribofuranoside attenuates experimental autoimmune encephalomyelitis via modulation of endothelialmonocyte interaction. J Neurosci Res 2006;84:614-25.

62. Yang C, Ling H, Zhang M, Yang Z, Wang X, Zeng F, et al. Oxidative stress mediates chemical hypoxia-induced injury and inflammation by activating NF- $\kappa b-C O X-2$ pathway in $\mathrm{HaCaT}$ cells. Mol Cells 2011;31:531-8.

63. Yang C, Yang Z, Zhang M, Dong Q, Wang X, Lan A, et al. Hydrogen sulfide protects against chemical hypoxia-induced cytotoxicity and inflammation in HaCaT cells through inhibition of ROS/NFкB/COX-2 pathway. PLoS One 2011;6:e21971.

64. Luo H, Guo P, Zhou Q. Role of TLR4/NF- $\kappa B$ in damage to intestinal mucosa barrier function and bacterial translocation in rats exposed to hypoxia. PLoS One 2012;7:e46291.

65. Tewari R, Choudhury SR, Ghosh S, Mehta VS, Sen E. Involvement of TNFa-induced TLR4-NF- $\kappa \mathrm{B}$ and TLR4-HIF-1a feed-forward loops in the regulation of inflammatory responses in glioma. J Mol Med (Berl) 2012;90:67-80.

66. Laderoute KR, Amin K, Calaoagan JM, Knapp M, Le T, Orduna J, et al. 5'AMP-activated protein kinase (AMPK) is induced by lowoxygen and glucose deprivation conditions found in solid-tumor microenvironments. Mol Cell Biol 2006;26:5336-47.

67. Miller EJ, Li J, Leng L, McDonald C, Atsumi T, Bucala R, et al. Macrophage migration inhibitory factor stimulates AMP-activated protein kinase in the ischaemic heart. Nature 2008;451:578-82. 